\section{Pobreza, desigualdades ou exclusão?}

Poverty, inequalities or exclusion?

Sonia Fleury ${ }^{1}$

0 artigo em debate pretende apresentar os desafios para as políticas públicas relativos à temática da pobreza, desigualdades sociais e saúde. Para tanto, introduz o problema da pobreza na Europa desde quando ele passa a ser objeto de intervenção estatal até o surgimento de amplos sistemas de proteção social que ficaram conhecidos como Estado do Bem-Estar Social. Em seguida, expõe as transformações na dinâmica do mercado de trabal ho resultantes dos processos de globalização e inovação tecnológica e suas conseqüências na introdução de uma forte tensão entre proteção social universal eas reduzidas possibilidades de integração atuais. No caso brasileiro, verifica-sea ten dência declinante da desigual dade de renda, apesar de mais de um terço da população continuar na condição de pobreza e das políticas públicas mostrarem baixa capacidade de promover eqüidade. No campo da saúde, as iniqüidades se referem às diferenças que colocam certos grupos em situações de discriminação e desvantagem no acesso aos serviços e que também reforçam as condições de vulnerabilidades destes grupos a certas enfermidades. M esmo com a existência de uma política universal como o SUS, as iniqüidades persistem de forma sistemática.

$M$ ais recentemente, os programas de transferência condicionada de renda têm merecido destaque, sendo consideradas políticas públicas mais apropriadas para o combate à pobreza, embora as investigações apontem evidências de importantes limitações e desafios em sua operacionalização, em especial, a inexistência de uma agenda social comum entre os diferentes atores envolvidos nas políticas sociais que permita a criação de políticas transversais de combate à pobreza.

Apesar do consenso acerca destas afirmativas, caberia a pergunta sobre se a pobreza é realmente nossa questão social. Colocada nestes termos, minharesposta seria queéa exclusão a questão social atual, mesmo que ela esteja fortemente associada à pobreza. No entanto, são fenômenos sociais distintos, e confundi-los pode ser o caminho para a ineficácia das políticas públicas.

Interessa-nos tratar o social a partir da sua emergência como "questão social", ou seja, como reconhecimento de novos problemas que emergem na arena política a partir da transformação de necessidades em demandas, processo esteque só pode ser realizado concomitantemente à própria construção dos novos sujeitos políticos. Portanto, a questão social passa a ser reconhecida quando politizada por novos atores que, através da construção de suas identidades, formulação de projetos e estratégias, repõem a problemática da integração e da necessi dade de recriar os vínculos sociais.

N este sentido, a emergência da questão social é sempre um analisador (no sentido analíticoinstitucional usado por Lourrau) porque desvela as contradições sociais e expõe as fragilidades da construção política de uma comunidade coesa.

$\mathrm{N}$ a América Latina, a questão social foi posta, historicamente, associada e delimitada pela reivindicação de um status sociopolítico para o trabal ho urbano, gerando políticas de seguro social que não se destinavam aos grupos mais pobres, como trabalhadores rurais, domésticos e autônomos.

A política em relação à classetrabal hadora vai combinar a repressão, exclusão e incorporação controlada da participação e das demandas sociais, gerando formas híbridas de relação de autoridade, o quepossibilita quea dependência pessoal sobreviva e dê sustentação até mesmo aos sistemas legais de proteção social que se pautariam, originariamente, na independência pessoal e na submissão à norma formal abstrata da cidadania. No desenvolvimento do sistema de proteção social brasileiro, este fenômeno manifestouse através da implantação de um regime de cidadania, regulada pelo Estado, a partir da inserção do trabalhador no mercado formal de trabal ho ${ }^{2}$ e decidadania, invertida ${ }^{3}$, representada pel as ações assistenciais que se destinaram àquel es excluídos pelo mercado e pelo padrão corporativo de institucional ização das políticas sociais.

O formato da proteção social vai ser uma combinação de integração barganhada e hierarquizada das diferentes frações dos trabalhadores urbanos e exclusão dos camponeses e trabaIhadores do mercado informal de trabalho. Este formato é conseqüência da heterodoxa composição do bloco no poder que implica em respeitar os interesses do setor agrário e manter intocadas as condições de exploração do trabal ho no campo.
${ }^{1}$ Escola Brasileira de Administração Pública, Fundação Getúlio Vargas. sfleury@fgv.br 
Por outro lado, as demandas pela industrialização e por melhores condições de reprodução da força de trabalho industrial, bem como as necessidades de legitimação política do governo, tornam a política social a moeda de troca na geração da lealdade necessária à consolidação do exercício do poder. Neste caso, mais do que um direito universal, inerente à condição da cidadania, a proteção social torna-se privilégio diferenciado para cada estrato particular da sociedade. Só com a democratização a sociedade brasileira projetou a construção de uma seguridade social, sendo os direitos sociais associados à condição de cidadania.

No entanto, a implantação destas políticas em um período depredomínio da ideologia liberal paralisou a modernização democrática do Estado e gerou expectativas frustradas por parte deuma população crescentementelocalizada nas periferias das grandes metrópoles. A crescente incorporação da temática da pobreza e sua centralidade na agenda política nas duas últimas décadas não deve eludir a questão social que está colocada, nos termos do questionamento da possibilidade de preservação da ordem e da autoridade institucional - ou governabilidade - e preservação da organização social.

A individualização da pobreza e seu tratamento de forma econômica (linhas e mapas) ou cultural (características e valores) separam este fenômeno tanto das condições de produção quanto das condições institucionais de proteção social. Paralelamente à individualização da pobreza, assistimos à individualização do risco ${ }^{4}$, através das reformas dos sistemas de políticas sociais de base mais coletiva em direção à associação entre contribuição e benefício.

A inexistência de perspectivas concretas de alteração radical das condições de produção da pobreza, como condição indispensável para o desenvolvimento material e político de nossas sociedades, denuncia a existência subjacente de algo mais profundo, que realmente se constitui em analisador dos limites da coesão em nossas sociedades.

É a situação de violência que experimentamos nos dias atuais, especialmente nas grandes cidades, gerando um sentimento generalizado de insegurança e medo, que pode ser tomada como a condição atual de emergência da questão social, requerendo estratégias de políticas públicas que possam responder a esta situação crítica e assegurar possibilidades de recriação da coesão social.

A associação entre pobreza, crimeorganizado eviolência reconduz as políticas sociais a uma função de apaziguamento do conflito urbano, desvirtuando sua condição de reconstrução da esfera pública democrática. N este contexto, a exclusão social - condição que sempre existiu e com a qual a sociedade latino-americana pôde conviver como natural - aparece como questão social, isto é, problemática que demanda como resposta seu equacionamento por parte do governo e da sociedade. Isto porque é a exclusão, enão a pobreza, que questiona e ameaça a organização social, a autoridade política e o projeto econômico.

A exclusão se refere à não incorporação de uma parte significativa da população à comunidade social e política, negando sistematicamente seus direitos de cidadania - envolvendo a igualdade de tratamento ante a lei e as instituições públicas - eimpedindo seu acesso à riqueza produzida no país.

De uma forma mais profunda, a exclusão implica a construção de uma normatividade que separa os indivíduos, impedindo sua participação na esfera pública. Trata-se de um processo relacional e cultural que regula a diferença como condição denão inclusão, apresentando também uma manifestação territorial, seja como gueto ou favela.

Esta fratura sociopolítica, que se manifesta na convivência em uma mesma sociedadedeuma dupla institucionalidade ${ }^{5}$, impede a constituição das dimensões nacional, republicana e democrática, retirando legitimidadeao exercício do poder e restringindo a esfera pública ${ }^{6}$.

Grande parte dos estudos econômicos e políticos tem se dedicado à questão da pobreza, tratando-a como uma questão de desigualdade, sem distinguí-la analiticamente da exclusão. No entanto, Boaventura de Souza Santos ${ }^{7}$ sublinha a diferença entre desigualdade e exclusão, já quea desigualdade é um fenômeno socioeconômico, que se assenta na noção de igualdade, enquanto a exclusão se funda no caráter essencial da diferença eéum fenômeno de civilização.

Um dos primeiros estudiosos dos processos sociais de "apartação" foi certamente Fannon", em seus trabalhos sobre a ordem e as identidades sociais que caracterizam o mundo colonial, nos quais ele introduz a questão central para a compreensão da exclusão, como um processo que despoja aos indivíduos de sua dimensão humana, impedindo-Ihes que se tornem sujeitos de seu processo social. Para Hannah Arendt ${ }^{9}$, os fundamentos da condição humana encontramse na relação entre o discurso e a ação, pois aí encontramos o lugar do sujeito. Por conseguin- 
te, se a apropriação discursiva é o fundamento da condição humana, é a proibição do discurso o que despoja os indivíduos de sua condição de atores, da possibilidade de inclusão em uma ordem simbólica relacional, constituída por uma trama de atose palavras. A constituição de sujeitos de ação, sua possibilidade de inserção, passa, necessariamente, pelo resgate de sua possibilidade discursiva.

Rejeitando a identificação de cultura como saber enciclopédico, Gramsci identifica-o à noção de civilitá como conjunto de modos de vidas, comportamentos e valores ideológicos originários da organização do trabalho e das relações de produção e ao papel adaptativo-educativo do Estado, na busca da adequação ente 0 aparelho produtivo e a moralidade das massas populares ${ }^{10}$.

Desta forma, os grupos excluídos estão, em geral, impossibilitados de participar das relações econômicas predominantes- no mercado, como produtores e/ou consumidores - e das relações políticas vigentes, os direitos de cidadania.

No entanto, a coexistência, em um mesmo grupo populacional, de situações de pobreza, ausência de direitos sociais ou de condições de exercêlos, e sua exclusão da comunidade sociopolítica, não nos deve confundir e levar-nos a pensar que se trata de um fenômeno simples, subordinado à dimensão econômica, o que implicaria em uma estratégia técnico-redistributiva de enfrentamento desta complexa condição.

Em países como os latino-americanos, em que a exclusão tem um forte conteúdo econômico, não é possível combater a exclusão sem a redistribuição da riqueza. No entanto, o combate à exclusão não se reduz a esta dimensão econômica, já que esta, apesar de ser a dimensão fundamental, não existe isolada do contexto sociocultural que a legitima e reproduz. Em outros termos, a concentração da riqueza éum fenômeno político, queimpedea constituição de sujeitos políticos capazes de reivindicar sua inserção na esfera pública.

A emergência de uma questão social requer e reivindica seu enquadramento por meio de políticas e instituições específicas, em geral, as chamadas políticas sociais. Por suposto, uma mesma questão será respondida de diferentes maneiras em contextos políticos, culturais einstitucionais distintos, gerando diversos padrões de proteção social.

Em uma mesma sociedade, encontramos movimentos contraditórios, cuja resultanteconformará a resposta à questão social colocada.
Assim, se por um lado encontramos um grande desenvolvimento das ciências sociais na mensuração da pobreza e na definição de estratégias individualizadas de focalização e reformas dos sistemas de política social em direção às coberturas individualizadas, por outro lado, assistimos ao crescente "cercamento" dos espaços públicos e privados, como estratégia de defesa patrimonial contra os pobres coletivizados como classes perigosas.

Não podemos desprezar o papel da "mídia" na reprodução sistemática de normas de exclusão ena reificação de identidades sociais polarizadas. A difusão de valores individualistas e de consumo, prevalecendo sobre normas solidárias, mina as possibilidades de construção de vínculos sociais que transitem esuperem a fratura urbana, que no Brasil foi denominada de "cidade partida".

No entanto, a emergência erecente proliferação de organizações e movimentos sociais solidários demonstram a capacidade de reação da sociedade e dos governos locais à ameaça de sua decomposição, recriando possibilidades de articulação social.

Ademais, observa-seque a dinâmica de lutae combate à exclusão possui uma dimensão emancipadora, capaz de gerar a constituição de novos sujeitos sociais e de novas formas de reivindicação do exercício dos direitos de cidadania, além de inaugurar possibilidades de alteração da dimensão institucional do Estado, dando lugar a novas formas de co-gestão pública ${ }^{11}$.

Portanto, a nossa questão social - a exclusão - requer o posicionamento de diferentes atores da sociedade, inaugura novas formas de sociabilidade, defineo campo estratégico delutas, constrói novos sujeitos e novas subjetividades, demanda o desenvolvimento de novos saberes e tecnologias disciplinares, produz novas estraté gias de reconstrução da ordem política e de enquadramento das demandas sociais e aponta no sentido de processos de transformação das estruturas institucionais estatais.

\section{Referências}

1. Lourrau R. El análise institucional. Buenos Aires: Amorrortu Editores; 1975.

2. Santos WG dos. Cidadania e Justiça. Rio de Janeiro: Editora Campus; 1979.

3. Fleury S. Estado sem cidadãos: seguridade social na América Latina. Rio de Janeiro: Editora Fiocruz; 1994.

4. Procacci G. Ciudadanos pobres, la ciudanía social y la crisis de los estados del bienestar. In: Soledad G, Steven L, editores. Ciudadanía, justicia social, identidad y participación, M adrid: Siglo XXI; 1999. 
5. Santos WG. 0 híbrido institucional brasileiro. In: Santos WG. Razões da desordem. Rio de Janeiro: Editora Rocco; 1993.

6. Fleury S. Legitimidade política, Estado e cultura. Bolívia: IDH/ PNUD; 2002.

7. Santos B de S. A construção multicultural da igualdade e da diferença. In: Anais do VI Congresso Brasileiro de Sociologia; 1995; Rio de Janeiro.

8. Fannon F. Os condenados da terra. $2^{a}$ ed. Rio de Janeiro: Editora Civilização Brasileira; 1979.

9. Arendt H. A condição humana. $6^{a}$ ed. São Paulo: Editorial Forense Universitária; 1993.

10. Buci-Glucksman C. Gramsci e o Estado. São Paulo: Paz e Terra; 1980.

11. Genro T. 0 novo espaço público - 21 teses para a criação de uma política democrática e socialista. Folha de São Paulo 1996 Jun 9.

Notas sobre cuidados no monitoramento de políticas e programas intersetoriais

Notes on careful monitoring of intersectoral policies and programs

Eleonor Conill ${ }^{2}$

Foi um prazer ler um texto que alia profundidade a um estilo claro, tornando mais fácil à aproximação de um tema tão complexo. Os programas de transferência condicionada de renda têm se expandido como uma estratégia de enfrentamento da pobreza no cenário da globalização. 0 pressuposto subjacente é de que seria mais efetivo prestar assistência condicionando-a ao uso de equipamentos sociais que potencializam 0 desenvolvimento humano de forma a facilitar a integração.

0 estabelecimento de condições para a obtenção de benefícios assistenciais não énovidade e o quemereceser destacado éa importância que estas propostas vêm adquirindo juntamentecom a ênfase em ações intersetoriais. M as, conforme assinalam as autoras, os resultados são ainda controversos.

Duas possibilidades me ocorrem para contribuir neste debate; a primeira se refere a assinalar algumas perspectivas e os limites do campo da avaliação em saúde no monitoramento dessas políticas; a segunda, trazer algumas informações recentes acerca dos efeitos da estratégia da saúde da família/PSF para a eqüidade, no caso brasileiro.

Primeiramente, penso ser importante um pequeno retrocesso histórico de forma a situar 0 contexto da difusão do relatório Lalonde no Canadá. Embora esterelatório seguidamenteseja referido como um marco para as políticas de promoção, vale a pena assinalar que, no momento de seu surgimento, o documento despertou duras críticas, pois enfatizava a importância das mudanças comportamentais individuais no estilo de vida (estratégia denominada de "victim blaming"). Sua difusão coincidia com o início do período de reformas neoliberais no qual, após um período de grande expansão do complexo médico-industrial sob financiamento estatal, 0 governo federal passou a reduzir drasticamente seu aporte monetário para as províncias. M as serão os próprios canadenses nas Conferências que se sucederam que se encarregarão de ampliar o sentido restrito com que a promoção havia sido tratada, enfatizando a importância do ambiente. Vêm desse país alguns dos melhores model os para avaliação de sistemas de saúde que mostram a inter-relação dos diversos subsistemas sociais na determinação da saúde/doença. Ao final, todo esse movimento colaborou para enfatizar a importância das ações intersetoriaise para que no campo da avaliação e da análise comparada fosse definida com maior precisão a diferença entre sistema de saúde e sistema de serviços. Isto determinou esforços no sentido de se obter indicadores que pudessem ser sensíveis a ações específicas dos serviços, bem como a construção de matrizes integradas de avaliação, tal como sugerido no texto.

Diferentementeda avaliação de atos médicos ou de tecnologias, a avaliação de políticas e programas sociais enfrenta de forma mais contundente pelo menos três desafios: a multifatorialidade do objeto de intervenção, a noção de julgamento devalor enquanto núcleo essencial da prática avaliativa e o fato de que as ações envolvem processos de trabal ho que visam contribuir para mudanças sociais.

Na tarefa de avaliar, a noção de "juízo" mescla-se à aparente objetividade da noção de "medida", tendo sido a preocupação com esta última a que tem predominado. A omissão em tratar a questão dos valores põe em plano secundário a avaliação ex-ante, minimizando a importância

\footnotetext{
${ }^{2}$ UniversidadeFederal de Santa Catarina. eleonorconill@yahoo.com.br
} 